\title{
Experimental Study on Flexural Behavior of Modified Recycled Concrete Beams
}

\author{
Shimin Zhang ${ }^{\mathrm{a} *}$, Xiaohui Peng ${ }^{\mathrm{b}}$ and Kangning Liu $^{\mathrm{c}}$ \\ (School of Civil Engineering, Xijing University, Xi'an 710123, China)

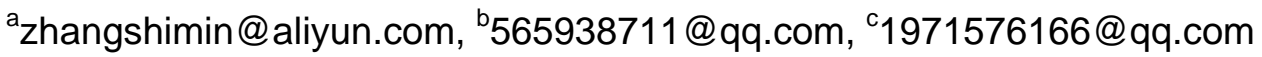

Keywords: Failure mode; Hybrid fiber; Flexural behavior

\begin{abstract}
With silicon powder content and the hybrid fiber content as parameters, will be 1 as ordinary concrete beams and the control group, three different content of silicon powder and 2 root hybrid fiber volume content of beam as the experimental group, the modification of the flexural performance of recycled concrete beams is analyzed, the results show that modified regeneration of recycled concrete and ordinary concrete beams and damage has obvious four stages of the process, and its basic mechanical process also accord with flat section assumption; And with silicon powder and the mixed hybrid fiber recycled concrete beams is made of modified flexural performance enhancements, cracking resistance and ultimate bearing capacity is better than that of recycled concrete beams is ordinary; And the ultimate bearing capacity of normal section of the calculated in accordance with the specification was consistent with the test results, the modified recycled concrete can be carried out in accordance with the specification design, provides a reference for engineering practice.
\end{abstract}

\section{Introductions}

With the rapid development of the construction industry, a large number of waste concrete has been produced every year due to demolition, transformation and other reasons, and there is no proper means to deal with it, which has caused the destruction of the ecological environment. And the production of concrete requires a lot of quarrying to make coarse aggregate, waste of resources [1].Therefore, the reuse of waste concrete is of great significance. At present, many scholars mainly for recycled concrete (RAC) material properties were extensive and in-depth research, but research for recycled concrete component and structural performance of a relatively small [2]. Ishill K. [3]by test that the normal section of reinforced beam flexural failure model and ordinary concrete difference. Yang Guixin and Wu Jin[4-5] studied the short-term stiffness and deflection of the beam through the flexural behavior of the RAC beam. In this paper, the flexural properties of the modified RAC beam are analyzed by adding different silica fume and mixed fiber, which provides a reference for engineering practice.

\section{Experimental Design}

Test Materials and Mix Ratio. The cement strength grade of Qinling Mountains brand 32.5R Portland cement, the standard curing 28d compressive strength can reach 36.5MPa; by using natural sand in sand, the fineness modulus of recycled coarse aggregate is 2.75; the waste concrete service for 15 years, after crushing, screening, washing and made the biggest the particle size is not greater than $31.5 \mathrm{~mm}$; natural aggregate by continuous gradation gravel; silica fume (SF) from Shaanxi Lin source microsilica Co. Ltd. Using CL- PCE superplasticizer polycarboxylate superplasticizer (PS); hybrid fiber (HF) is the three branch of anti-aging fiber and polypropylene modified polypropylene fiber rough TANK according to the mass ratio of 3:7 mixture. In order to study the effect of 2 factors on the flexural properties of modified RAC simply supported beam, the ratio of silica fume content and the content of hybrid fiber were considered respectively, and the tests used in the test were shown in table 1 . The performance of steel beam specimens were measured in the electronic universal testing machine mechanics laboratory of Xi'an University Of Architecture And Technology materials, its basic properties such as table 2, the mechanical properties of concrete 
material and the corresponding as shown in table 3.

Table 1 Ratio of normal section to bent beam

\begin{tabular}{cccccccccc}
\hline Beam & C & S & NA & RA & B & SF & HF & PS & W \\
\hline BB-3 & 500 & 466 & 600 & 600 & - & - & - & - & 215 \\
BB-9 & 422 & 487 & 627 & 627 & 0 & 25 & - & 8.1 & 187 \\
BB-10 & 405 & 485 & 624 & 624 & 0 & 49 & - & 8.1 & 187 \\
BB-11 & 396 & 485 & 624 & 624 & - & 59 & - & 8.1 & 187 \\
BB-12 & 405 & 485 & 624 & 624 & - & 49 & 0.9 & 8.1 & 187 \\
BB-13 & 405 & 485 & 624 & 624 & - & 49 & 3 & 8.1 & 187 \\
\hline
\end{tabular}

Table 2 Mechanical property index of steel bar

\begin{tabular}{cccc}
\hline diameter/mm & Yield strength $/ \mathrm{MPa}$ & ultimate strength $/ \mathrm{MPa}$ & Modulus of elasticity $\times 10^{5} \mathrm{MPa}$ \\
\hline 6 & 454 & 518 & 2.12 \\
12 & 345 & 538 & 2.11 \\
16 & 415 & 625 & 2.04 \\
\hline
\end{tabular}

Table 3 Mechanical properties of RAC

\begin{tabular}{cccc}
\hline Factor & $\begin{array}{c}\text { Cube Strength } \\
\text { /MPa }\end{array}$ & Prism compressive strength $/$ MPa & Modulus of elasticity $\times 10^{4}$ MPa \\
\hline BB-3 & 33.2 & 30.9 & 3.24 \\
BB-9 & 34.9 & 23.1 & 3.46 \\
BB-10 & 36.4 & 26.5 & 3.61 \\
BB-11 & 38.8 & 28.6 & 4.23 \\
BB-12 & 34.7 & 20.9 & 3.71 \\
BB-13 & 35.3 & 20.5 & 4.06 \\
\hline
\end{tabular}

Component Design. Normal section of the bending properties of the specimens were made of 6 beams, BB-1 common RAC beam as the control group, the rest of the modified RAC beam as the experimental group, the reinforcement ratio was $1.76 \%$ and the replacement rate is set at $50 \%$, the size of the component design as shown in figure 1.

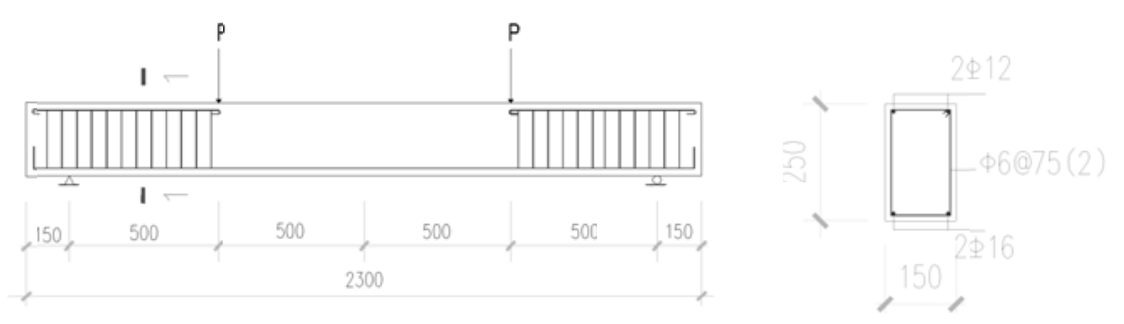

Figure 1. Specimen of bent beam

Loading Scheme and Layout of Measuring Points. The specimens are loaded in the structural laboratory of Xi'an University Of Architecture And Technology. For the oblique section test of the beam, we use two points loading. A force sensor is arranged between the vertical jack and the distributing beam, and a displacement gauge is arranged at the loading point, the left and the right side of the beam, and the middle and the bottom of the beam span. According to the current codes, the ultimate load and cracking load of beams are calculated and classified according to the standard of test method for concrete structures (GBJ 50152-92). Before the first loading on beam pre-loaded to see the instrument is working properly, the official in the loading process in the beam before cracking by using the load increment of $5.0 \mathrm{kN}$ loading, when the cracking phenomenon after loading with load increment $10 \mathrm{kN}$, when close to the estimation of ultimate load, reduce the load increment to $5.0 \mathrm{kN}$, until the specimen completely damage.

\section{Test results and Analysis}

Test Phenomenon. The modified RAC beam and ordinary RAC beam flexural failure phenomenon is basically the same, as shown in Figure 2, are elastic stage, crack stage, yield stage and ultimate stage, and the tensile steel yield concrete compression zone, crisp muster, beam failure. The 
cracking load of common RAC beam is $20 \mathrm{KN}$, and as the load continues to increase, the cracks gradually increase and continue to extend upwards. When the load reaches $120 \mathrm{KN}$, the main tendons yield, and when BB-3 reaches $123 \mathrm{KN}$, the beam breaks. BB-9, BB-10 and BB-11 with different content of silica fume RAC beam, when the load increased to 25KN.Initial cracks appear in the middle of the beam, the crack width is less than $0.05 \mathrm{~mm}$, when the load increased to about $125 \mathrm{KN}$, the main reinforcement yield; when the load reaches $135 \mathrm{KN}$, the specimen of destruction. For BB-12 and BB-13 containing hybrid fibers, the initial crack load is 33KN, and when the load reaches $130 \mathrm{KN}$, the main tendon yield; when the load increases to $140 \mathrm{KN}$, the specimen beam is destroyed.

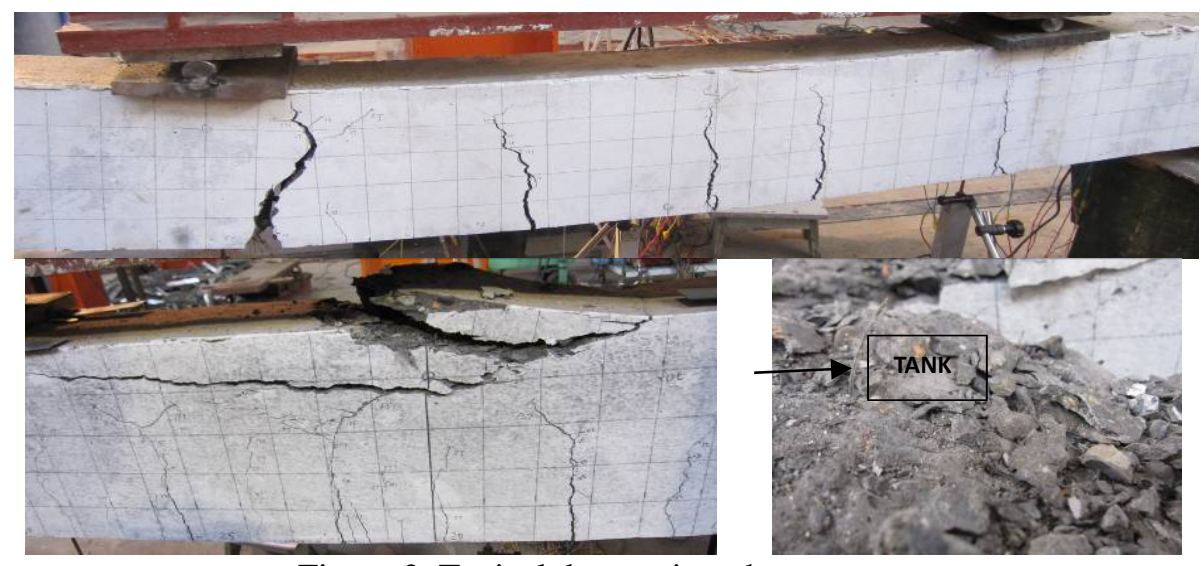

Figure 2. Typical destruction phenomenon

Comparative Analysis of Load Deflection Curves. The physical and mechanical properties of reactive mineral silicon powder are improved by improving the internal structure of RAC and strengthening its compactness. As shown in Figure 3, after a comparison of silica fume content were $4 \%, 8 \%$ and $10 \%$ of BB-9, BB-10 and BB-11 and RAC BB-3, in RAC adding silica fume to yield strength and ultimate strength of RAC are improved as shown in Table 4, especially the silicon content of $4 \%$ BB-9 beam, improve bearing capacity. However, with the increase of silica fume content, the bearing capacity decreased slightly, indicating that a certain amount of silica fume is beneficial to the improvement of the bearing capacity of RAC beams. For the effect of fiber mixing on RAC, as shown in Figure 3, the initial deflection increases linearly with increasing load, but with the load continuing to increase, the deflection appears to be sudden. The incorporation of hybrid fibers restricts the development of cracks, maintains the overall performance of the beam and reduces deflection of the beam. Content of hybrid fiber was $0.3 \%$ and $1 \%$ of the BB-12 beam and BB-13 beam, compared with ordinary RAC, the yield strength and ultimate strength did not improve, but with the increasing dosage of cracking load of hybrid fiber decreases, as shown in table 4. The corresponding deformation deflection, cracking load and yield load corresponding with the mixed fiber content increased in the case of the change is not obvious, and the deflection corresponding to the ultimate load, add hybrid fiber, its deformation decreases, the deflection is reduced. At the same time, it played an important role in the tensile hybrid fiber with RAC [6-7].

Table 4 Effect of SF on bearing capacity of RAC beam

\begin{tabular}{cccc}
\hline Specimen number & Cracking moment $/ \mathrm{kN} . \mathrm{m}$ & $\begin{array}{c}\text { Yield moment } \\
/ \mathrm{kN} . \mathrm{m}\end{array}$ & $\begin{array}{c}\text { Ultimate bending moment } \\
/ \mathrm{kN} . \mathrm{m}\end{array}$ \\
\hline BB-3 & 5.64 & 28.26 & 31.32 \\
BB-9 & 8.36 & 30.94 & 35.06 \\
BB-10 & 7.17 & 29.45 & 32.51 \\
BB-11 & 3.77 & 30.47 & 34.55 \\
BB-12 & 7.85 & 31.15 & 35.91 \\
BB-13 & 5.13 & 30.64 & 34.72 \\
\hline
\end{tabular}





Figure 3. Comparison of load displacement curves of RAC beams

Calculation and Comparative Analysis of Ultimate Bending Moment. According to the reference code[8], the ultimate value of flexural strength of Single Reinforced Rectangular Beam under normal section is as follows:

$$
\begin{aligned}
& \sum X=0 \quad \alpha_{1} f_{c} b x=f_{y} A_{s} \\
& \sum M=0 \quad M \leq M_{u}=\alpha_{1} f_{c} b x\left(h_{0}-x / 2\right)=f_{y} A_{s}\left(h_{0}-x / 2\right)
\end{aligned}
$$

The ultimate bearing capacity of the modified recycled concrete beam calculated from the formula (1) and (2) is compared with the experimental value, as shown in table 5. The incorporation of silica fume which makes the change of ultimate moment of RAC beam are improved, especially the silicon content of 4\% RAC specimens were the most significant, but with the increase of silicon content, the ultimate moment value declined, indicating silica content too much is not conducive to the change of cross section of RAC beam flexural performance. The incorporation of hybrid fiber greatly improves the flexural properties of RAC beams, and the two different volumes of hybrid fibers in the experiment have little change in the flexural properties of the beams. But overall, the basic test value that is greater than the calculated value, calculation of normal section of ordinary concrete beam according to the specification in the bending bearing capacity formula is also suitable for the modification of recycled concrete beam specimens, verifying the formula for reliability modification of recycled concrete.

Table 5 Comparison of ultimate moment test and calculation

\begin{tabular}{cccc}
\hline Number & $M_{u}^{0}$ & $M_{u}^{c}$ & $M_{u}^{c} / M_{u}^{0}$ \\
\hline BB-3 & 31.32 & 30.97 & 1.01 \\
BB-9 & 35.06 & 32.36 & 1.08 \\
BB-10 & 32.51 & 31.67 & 1.03 \\
BB-11 & 34.55 & 30.82 & 1.12 \\
BB-12 & 35.91 & 33.11 & 1.08 \\
BB-13 & 35.72 & 32.75 & 1.09 \\
\hline
\end{tabular}

\section{Conclusions}

Modification of recycled concrete beams and ordinary recycled concrete beams, in elastic stage, crack stage, yield limit stage and four stage by the obvious characteristics.

The performance of modified recycled concrete beams is superior to that of ordinary recycled concrete in crack resistance and ultimate bearing capacity. Increase the deflection of recycled concrete beams with the incorporation of silica fume, but ductility relatively decreased; and the hybrid fiber two crack developments, the deformation of beam deflection decreases, reduce, enhance the ductility of the beams.

The ultimate bending moment of beam specimen test results were compared with the calculated results, the calculated value is less than the test value, and the difference is not big, show that the calculation formula of normal section of the wrist of ordinary concrete standard in bearing capacity, is also suitable for the modification of recycled concrete, provide a reference for practical engineering application. 


\section{Reference}

[1] Wang Jiachun, Zhang Chun. Test of recycled concrete beams strengthened by [J]. Journal of Lanzhou University of Technology, 2016, 42 (2): 130-134.

[2] Xiao Jian Zhuang, Lei Bin, et al. Recycled concrete beam bending theory and reliability analysis [J]. Journal of Southeast University (NATURAL SCIENCE EDITION), 2010,40 (6): 1247-1251.

[3], Ishill, K.et, al., characteristic, of, RC, beam, with, recycled, coarse, aggregate[C]., Proceeding, of, the,, 25th, JSCE, Flexible, Annual, Meeting., Branch1998:886-887., Kanto

[4] Yang Guixin, Wu Jin, ye Qiang. Study on short-term stiffness of recycled coarse aggregate reinforced concrete beams [J]. Proceedings of the civil engineering society, 2010,43 (2): 55-63.

[5], Yang Guixin, Wu Jin, ye Qiang. Study on calculation method of deflection of recycled concrete beams [J]. Engineering mechanics, 2011, 28 (2): 147-151.

[6] Fan Yujiang, Wang Sheliang, Yu Yang, Zhang Bo. Experimental study on enhanced performance of recycled concrete beams reinforced with [J]. Experimental mechanics, 2013,28 (3): 390-401.

[7] Zhou Jinghai, Zhang Dong, Yang Yongsheng. Waste fiber recycled concrete test beams [J]. Journal of Shenyang Construction University (NATURAL SCIENCE EDITION) 2013, 29 (2): 290-296.

[8] GB50010-2010. Code for design of concrete structures [S]. Beijing: China Construction Industry Press, 2010. 